\section{Non-clostridium difficile pseudomembranous colitis responding to both vancomycin and metronidazole}

We describe a patient with pseudomembranous colitis in whom Clostridium difficile could not be detected.

\section{Case report}

A previously fit 15 -year-old Asian girl presented with acute abdominal pain. At operation bilateral ovarian cysts were removed and a coincidental uninflamed enterogenous cyst with its related ileum was resected. Cephazolin sodium ( $500 \mathrm{mg}$ intravenously every six hours) and metronidazole (500 $\mathrm{mg}$ suppositories, eight-hourly) were given to prevent wound sepsis and were continued for five days because of slight intraperitoneal soiling. Recovery was uneventful and she was discharged seven days after operation.

Eight days later she was readmitted with severe dehydration and a smallbowel obstruction. Rehydration was started (7 litres intravenous fluid in 20 hours), but her condition suddenly deteriorated (blood pressure 70/40 $\mathrm{mm} \mathrm{Hg}$, pulse $150 /$ minute, temperature $39 \mathrm{C}$ ) and her abdomen became acutely tender; rectal examination showed grey gelatinous material. Immediate laparotomy confirmed an adhesive small-bowel obstruction with no evidence of strangulation or intra-abdominal sepsis; the colon was collapsed and appeared normal. One dose of gentamicin ( $80 \mathrm{mg}$ intravenously) was given before operation, followed by cephazolin sodium $(500 \mathrm{mg}$ intravenously every six hours) and metronidazole ( $500 \mathrm{mg}$ intravenously every 12 hours) for two days. The day after treatment was started she had $1600 \mathrm{ml}$ of watery diarrhoea containing membranous material, abdominal tenderness, and a temperature of $38 \mathrm{C}$. Sigmoidoscopy showed no abnormality, apart from sparse membranes. These symptoms continued for four days despite supportive non-specific treatment, when vancomycin $(250 \mathrm{mg}$ orally, 6hourly) was started with good effect (figure). Treatment was stopped after four days because of slight deafness but symptoms recurred. Metronidazole (500 mg intravenously every eight hours) then induced a complete and permanent remission.

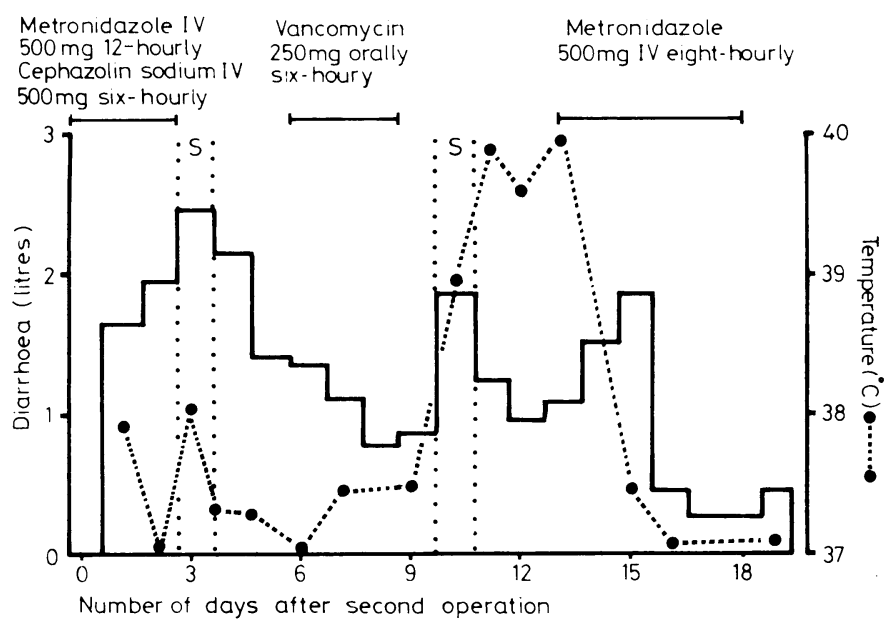

Clinical course and response to treatment of diarrhoea (- $\longrightarrow$ ) and temperature (- - - ).

$S$ represents the timing of specially tested stool samples.

On routine testing of six stool cultures no growth of $\mathrm{Cl}$ difficile, $\mathrm{Cl}$ perfringens, Staphylococcus, Salmonella, Shigella, Campvlobacter, Yersinia, yeasts, Giardia, or amocbae was found. Two stool cultures analysed at Northwick Park Hospital were both negative for stool cytotoxin and $C l$ difficile, using accepted techniques. ${ }^{1}$ In addition, $0.5 \mathrm{ml}$ aliquots of a $1 / 10$ dilution of these separate stool samples were administered orally to male Syrian hamsters that had been pretreated with clindamycin. All animals survived to 12 days, indicating absence of $\mathrm{Cl}$ difficile in the samples. Subsequently, all animals were challenged with a toxigenic strain of $C l$ difficile and all died within three days with a haemorrhagic caecitis, thus proving their sensitivity to the organism. Histological appearances were those of mild nonspecific mucosal colitis in the rectum, and inflammatory debris, with suggestion of polymorphs and fibrin aligned in columns, in the membrane.

\section{Comment}

Antibiotic-induced diarrhoea is usually a benign self-limiting condition, whereas pseudomembranous colitis may be life-threatening. The diagnosis of pseudomembranous colitis depends on the clinical picture backed up by histology (often unreliable owing to rectal sparing) or on the presence of $\mathrm{Cl}$ difficile in the stool, together with a cytopathic toxin neutralised by $\mathrm{Cl}$ sordellii antitoxin. ${ }^{2}$ The clinical picture and membrane histology in our patient strongly suggested the diagnosis of pseudomembranous colitis, but repeated bacteriological studies for $\mathrm{Cl}$ difficile were negative, most of these being taken before vancomycin treatment was started. Other clostridial species have been implicated in antibiotic colitis both in $\operatorname{man}^{3}$ (Cl perfringens type $\mathrm{C}$ ) and in animals ${ }^{4}$ (Cl histolyticum) but neither was present in our patient.

Thus there remains a possibility that a pseudomembranous type of colitis exists which is mediated by another organism(s) but which, like $\mathrm{Cl}$ difficile, responds to both vancomycin and metronidazole. This possibility is supported by a recent report of non-Cl difficile psuedomembranous disease localised to the rectum after treatment with metronidazole suppositories. ${ }^{5}$ Our patient's condition appeared to follow her first operation, as pseudomembranes were noted before the second operation for obstruction, and hence it may have been initiated by either cephazolin sodium or metronidazole. The therapeutic response to metronidazole does not necessarily exclude it as a causative agent.

The absence of $\mathrm{Cl}$ difficile from the stools should not preclude vancomycin (or metronidazole) treatment in severely ill patients with a pseudomembranous type of colitis.

We thank Dr M Kershaw and Dr A Price for the histological reports. S P Borriello acknowledges the support of Upjohns International.

1 Willey SH, Bartlett JG. Cultures in Clostridium difficile in stools containing a cytotoxin neutralised by Clostridium sordelli antitoxin. $\mathcal{F}$ Clin Microbiol $1979 ; \mathbf{1 0}: 880-844$.

${ }^{2}$ Kappas A, Shinagawa N, Arabi Y, et al. Diagnosis of pseudomembranous colitis. Br Med $\mathcal{F}$ 1978; : $675-8$.

${ }^{3}$ Schwartz JN, Hamilton JP, Fekety R, et al. Ampicillin-induced enterocolitis: implications of toxigenic Clostridium perfringens, type C. $\mathcal{F}$ Pediatr 1980;97:661-3.

4 Knoop FC. Clindamycin-associated enterocolitis in guinea pigs: evidence of a bacterial toxin. Infect Immun 1979;23:31-3.

${ }^{5}$ Thomson G, Clark A, Hare K, Spilg WG. Pseudomembranous colitis after treatment with metronidazole. $\mathrm{Br}$ Med $\mathcal{F} 1981 ; 282: 864-5$.

(Accepted 9 fune 1981)

St Mary's Hospital (Harrow Road), London W9 3RL

R K S PHILLIPS, FRCS, surgical registrar

G GLAZER, FRCs, consultant surgeon

Clinical Research Centre, Harrow, Middlesex HA1 3UJ

S P BORRIELLO, BSC, PHD, research fellow

\section{Azathioprine-induced shock}

Acute hypersensitivity reactions, including fever, rigors, and myalgia have been reported with azathioprine treatment. ${ }^{1-4}$ We report two cases of severe reaction caused by azathioprine in patients with rheumatoid arthritis, in whom pronounced hypotension was a dominant feature. To our knowledge this has been reported only once before. ${ }^{5}$

\section{Case reports}

Case 1-The patient, a 54-year-old woman, had had seropositive erosive rheumatoid arthritis for 14 years. Mild hypertension had been present for seven years, and blood pressure varied between $150 / 90 \mathrm{~mm} \mathrm{Hg}$ and $160 / 100 \mathrm{~mm} \mathrm{Hg}$. The arthritis was increasingly active, gold had been ineffective, and D-penicillamine had produced proteinuria, so azathioprine $50 \mathrm{mg}$ daily was started. Other medication was chlorothiazide, potassium chloride, propranolol, ibuprofen, naproxen, and prednisolone $7 \mathrm{mg}$ daily. 